\title{
Costs Analysis of Fibrin Sealant for Prevention of Anastomotic Leakage in Lower Colorectal Surgery
}

This article was published in the following Dove Press journal:

Risk Management and Healthcare Policy

\author{
Saswat Panda (ID) \\ Mark P Connolly $\mathbb{D}^{1,2}$ \\ Manuel G Ramirez ${ }^{3}$ \\ Juan Beltrán de Heredia ${ }^{4}$ \\ 'Global Market Access Solutions LLC, \\ Charlotte, NC, USA; ${ }^{2}$ University of \\ Groningen, Department of Pharmacy, \\ Unit of Pharmacoeconomics, Groningen, \\ Netherlands; ${ }^{3}$ Global HEOR Advanced \\ Surgery, Baxter Health Care \\ Corporation, Deerfield, MA, USA; \\ ${ }^{4}$ General Surgery Department, Hospital \\ Clinico Valladolid, Valladolid, Spain
}

Introduction: Postoperative anastomotic leaks remain a common and serious complication of colorectal surgeries and are a major cause of mortality and morbidity of these procedures. Anastomotic leaks (AL) have been extensively studied; however, there has been no significant reduction in their prevalence over time. In addition, there is a significant economic burden from AL attributed to the need for repeat surgery, radiologic intervention and lengthened hospital stay. We conducted a comparative cost analysis of patients undergoing colorectal surgery with anastomosis, with the application of fibrin sealant (FS) to the sutured anastomosis versus not treating the sutured anastomosis with FS.

Methods: The deterministic decision-tree model was populated with clinical data including operating room time, hospitalization days, occurrence of AL, need for revision surgery, blood products and radiologic interventions to treat the $\mathrm{AL}$ in lower colorectal surgery. A systematic literature review was conducted to identify appropriate studies with these variables.

Results: The average cost per case treated lower colorectal surgery with fibrin sealant glue $10 \mathrm{~mL}$ Tisseel ${ }^{\circledR}$ and those not treated with a fibrin sealant after suturing the anastomoses was $€ 3233$ and $€ 4130$, respectively, for resource expenses paid by the healthcare system. This would suggest potential savings of $€ 897$ per surgery, achieved through the application of FS to the sutured anastomosis for preventing AL following colorectal surgery.

Conclusion: Application of FS to the sutured anastomosis in lower colorectal surgery resulted in a decrease in post-operative $\mathrm{AL}$, and cost savings based on a reduction in hospitalization days, a reduction needing: revision surgery, radiologic intervention and blood products to treat AL.

Keywords: fibrin sealant, anastomoses, cost analysis, budget impact, colorectal surgery, colorectal cancer

\section{Background}

Postoperative anastomotic leaks (AL) remain a common and serious complication of lower colorectal surgeries, as they are a major cause of mortality and morbidity of these procedures. Anastomotic leaks have been extensively studied; however, it is unclear whether there has been any significant reduction in their incidence over time. ${ }^{12,42}$ Leak rates vary across anastomotic sites, ranging from $3 \%$ to $29 \%$ for the colon, $3,8,17,24,43$ and $8 \%$ to $41 \%$ for the rectum. ${ }^{22,42}$ In a study of elderly patients living in the Netherlands, it was estimated that in patients undergoing colorectal surgery, patients $<75$-years and patients $\geq 75$-years had approximately $7.4 \%$ AL rate post colon surgery. Patients $<75$-years undergoing rectal surgery had an AL rate of $11.4 \%$, versus $8.1 \%$ in the $\geq 75$-years group. ${ }^{12}$ Patients developing AL have significant morbidity up to $56 \%{ }^{11}$
Correspondence: Mark P Connolly Global Market Access Solutions LLC, Charlotte, NC, USA

Email mark@gmasoln.com 
and poor functional outcomes such as poor bowel function impacting digestion. ${ }^{38} \mathrm{AL}$ following colorectal resection is also reported to have a significant mortality rate of $6-22 \%{ }^{12}$

The economic burden of AL can be significant. Several studies reported that postoperative AL results in prolonged hospital stays, the need for radiologic interventions and occasionally revision surgery, can have significant costs in addition to their clinical importance..$^{20,23,42}$ A previous cost analysis demonstrated that the burden of AL per 1000 patients in the US was \$28.6 million in hospitalization and readmission costs. ${ }^{19}$ The costs are likely to be higher if indirect productivity costs were taken into consideration.

There are different recommendations for preventing AL; however, there is a lack of decisive suggestions backed by clinical studies to identify clinical best practice. ${ }^{5}$ Some of the recommendations include over-sewing across the staple-line and the use of fibrin sealants. Currently, there are differences in opinion among surgeons, where some opt to use fibrin sealant over the anastomoses for rectal surgery, while some do not use it. As such, there have been several studies investigating fibrin sealant's use in preventing anastomotic leaks in rectal surgeries. ${ }^{4,20,23,31}$

Fibrin sealant consists of fibrinogen and thrombin, loaded into two syringes with tips forming a common port. ${ }^{39}$ This formulation was designed to mimic the natural hemostasis and wound healing process and aid in closures of surgical incisions. ${ }^{6}$ In Spain, fibrin-based biological adhesives are authorized for use in clinical practice for many indications for achieving hemostasis and tissue sealing during the surgical treatment. ${ }^{31}$ Various studies have suggested a relationship between fibrin sealant to seal over sutured ileocolic and colocolic anastomosis. ${ }^{35}$ To study treatment practices and resource allocations in this area, we conducted a comparative cost analysis based on differences in outcomes following colorectal surgery, where FS is used to seal over the anastomosis compared to no use of sealant. A systematic literature search was performed and studies reporting anastomotic leaks were reviewed to identify relevant outcomes to include in the cost analysis using Spanish cost data.

\section{Methods}

\section{Literature Review}

The economic evaluation of Tisseel $^{\circledR}$ was based on a systematic review of prospective, randomized comparative efficacy studies in lower colorectal surgery. Relevant outcomes including hospital resource use metrics were identified and evaluated for use in the economic evaluation comparing the use of fibrin sealant with no fibrin sealant.

\section{Search Strategy}

A systematic literature search of prospective and randomized studies in which the economic impact of employment of fibrin sealant in colorectal surgery was conducted, including its impact on metrics such as hospital stay, surgical time, presence of AL, reoperation need, use of blood products and radiological interventions, to identify clinical studies reporting outcomes from colorectal surgery (rectal/rectum surgeries (between the caudal margin of the tumor and the anal verge)) in which fibrin sealants were used as hemostatic agent, compared standard of care applying PRISMA criteria for use in our cost analysis. ${ }^{25}$ PubMed, Google Scholar, Embase and Cochrane databases were searched, and 416 articles were found; 414 were discarded for different reasons (see Figure 1.) This search was performed for the period January 1, 1980 to June 6, 2018 using the following search terms: colorectal cancer, anastomosis, rectal anastomosis, colorectal surgery, rectum surgery, fibrin sealant, fibrinbased biological adhesive, patients, cost analysis, costutility analysis, cost, and Boolean terms such as OR and AND. Comparative studies identified in peer-reviewed manuscripts were reviewed to identify surgical outcomes. Quality assessment was performed for included studies using checklists provided by the National Heart, Lung, and Blood Institute. ${ }^{30}$ Appendix A1-A3 includes search terms and strategy.

\section{Data Extraction}

Identified studies were reviewed by two independent reviewers. Discrepancies between reviewers were resolved by a third-party adjudicator. The first author of each study identified was contacted via email to obtain additional unreported study outcomes. Studies not reporting appropriate outcomes necessary to perform a cost analysis (eg, length of hospitalization, radiological intervention, etc.) were excluded from this analysis.

Articles were excluded for reasons including inappropriate results, non-English-language or not translatable, included pediatric subjects, having outcomes which were not related to $\mathrm{AL}$, and if the study was not properly designed (eg, a case study or study with no comparison). Four articles and three studies were identified specific to Tisseel being used for rectal anastomosis closure following lower colon resection. Of these, only two studies were appropriate for use in a meta-analysis to determine AL rate, as one study had inappropriately presented 


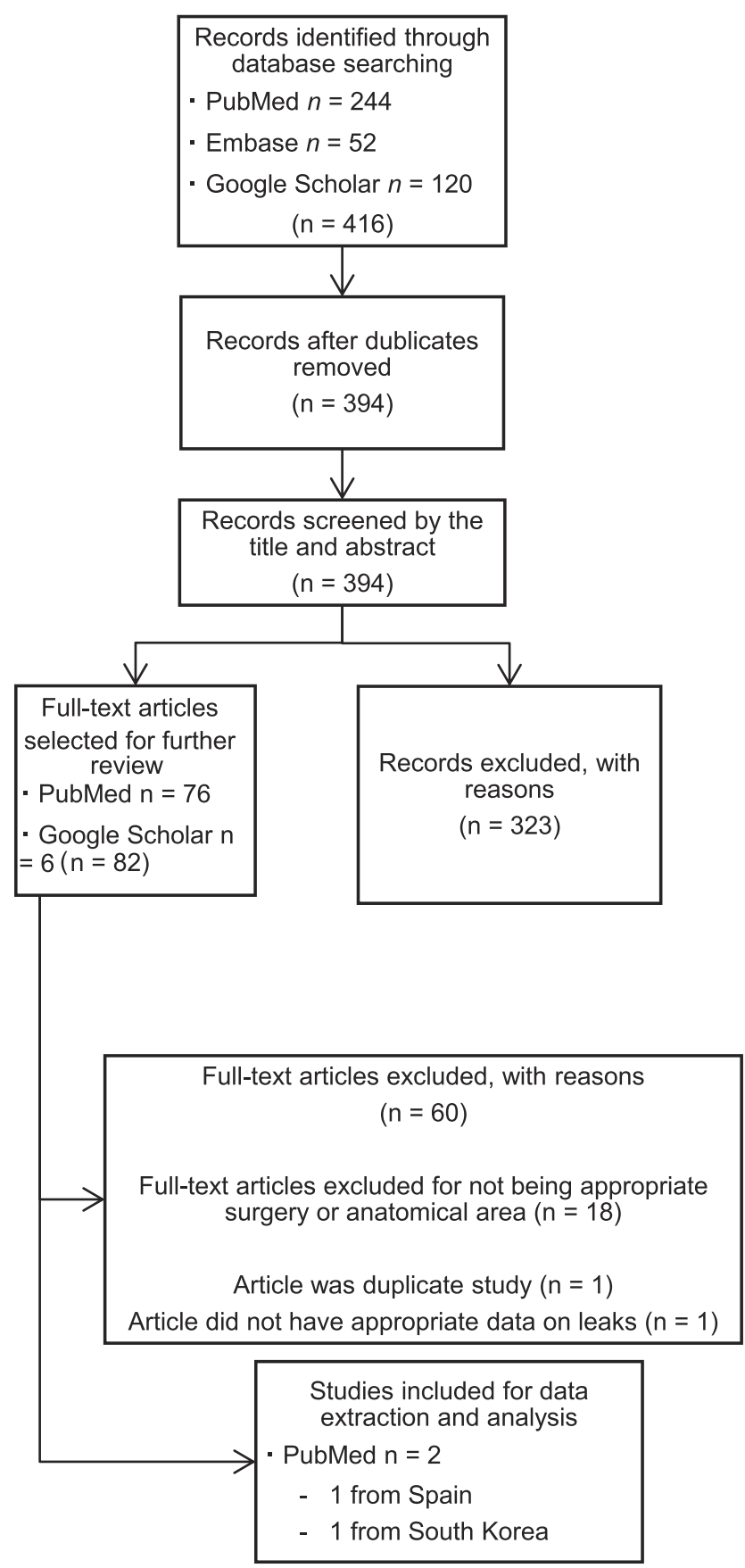

Figure I PRIMSA flow diagram for colorectal anastomoses studies which compared fibrin sealant used for sealing anastomoses.

data and design, and one study was found to be presenting data from the same study. ${ }^{20,23}$ The other 18 studies were not appropriate for a comparative cost analysis but were studied qualitatively and are mentioned in the discussion.

\section{Clinical Inputs}

Two randomized studies were identified that reflect current treatment practices for rectal resection patients with anastomosis and included appropriate outcomes on which to perform a cost analysis of fibrin sealant. ${ }^{23,31}$ The Oliver et al study was chosen for use in the model as it represents the Spanish population. A significant difference in $\mathrm{AL}$ rates of $18.8 \%$ and $52.5 \%$ for fibrin sealant and controls, respectively, have previously been reported. ${ }^{31}$ The revision rate input was also reported in this study, whereby revision surgery was required in 2 of $16(12.5 \%)$ patients receiving Tisseel, and 9 of 21 $(42.9 \%)$ patients that received no fibrin sealant to close the anastomoses. ${ }^{31}$

Clinical outcomes that were not reported in the Oliver study were identified from other studies with a similar patient population. Hospitalization lengths of 9 days and 9.5 days for Tisseel versus the cohort that did not receive any fibrin sealant were found from the study by Kim et al. ${ }^{20,23}$ The study reported by Angelini et al reported estimates on bleeding during rectal surgeries which employ fibrin sealant $(0.5 \%)$ vs no sealant $(0.7 \%){ }^{4}$

\section{Cost Data Inputs}

Costs for surgery and hospitalization for Spain were found in a study by Ielpo et al, which provides average costs per rectal resection surgery (€3506) and subsequent hospitalization (€266 per day) for a sample of 113 patients. $^{21}$ The cost of RBC transfusion (€368) has been calculated and published by Ribed-Sanchez et al $^{33}$ Tisseel costs, of $€ 341$ for $10 \mathrm{~mL}$ formulation which is the dose used in the rectal surgeries conducted in both the Oliver and the Kim study ${ }^{23,31}$ was provided by Baxter Spain. The cost of Tisseel includes the disposable applicator and the fibrin sealant formulation. The cost of radiologic interventions to treat leaks was found to be $€ 1045$ in a published report by the managing director of Navarra Health Service-Osasunbidea. ${ }^{29}$

\section{Modeled Cost Analysis}

An excel-based decision-tree model was developed to investigate the costs of using fibrin sealant (Tisseel, Baxter, Westlake Village, CA) for preventing AL in colorectal surgery. The model compares the costs of conducting the surgery and using a sealant to seal over the sutured anastomoses, versus using no sealant, and its effects on outcomes such as $\mathrm{AL}$, bleeding requiring transfusion, hospital length of stay, radiologic intervention and the need for revision surgery. The modeled cohort is based on patients with an average age of 64.3 years undergoing rectal resection surgery requiring rectal anastomosis. ${ }^{31}$ The model used the previously mentioned clinical and cost inputs to project the cost-differences for 
choosing to apply Tisseel for sealing of rectal anastomoses versus not using any sealant at all, for preventing potential anastomotic leaks.

To explore uncertainty around our analysis, we performed bootstrapping to the trial data reported from the study by Oliver et al, to generate confidence intervals (CI) from the average cost per case analysis. The simulated larger sample populations were calculated by conducting repeated sampling using bootstrapping to generate 500 samples from replications of the clinical trial data. ${ }^{9}$ The approach is used to generate larger sampling of the original trial results which are then randomly drawn from the sample to generate confidence intervals for the average cost per treatment intervention. Costs were then applied to the bootstrapped samples and a mean cost difference with a confidence interval is presented to give a measure of the stability and range of this value. This approach was taken over a sensitivity analysis as the costs, eg, per day hospitalization cost, are the same in both arms of our model; consequently, there would not be valuable information gained from varying these parameters.

\section{Results}

The disaggregated costs per person treated with fibrin sealant and no fibrin sealant after suturing the anastomoses, for radiologic interventions, red blood cell (RBC) transfusions, revision surgery and length of stay (LOS) in the hospital are described in Table 1. Based on the prevalence of radiologic intervention adjusted for actual leaks, we estimate that there is a $€ 351$ per case difference between Tisseel versus no fibrin sealant. For the Tisseel group, there is also a $€ 1064$ reduction in potential revision surgeries necessitated from leaks and a reduction of $€ 133$ attributed to the lower number of hospitalization days. There is a very small cost difference in red blood cell transfusions between groups, with the Tisseel group having a greater cost of approximately $€ 1$. The total cost savings for the Tisseel group was $€ 1208$ after an investment cost of $€ 341$ per patient. The results presented here are based on secondary data and are point estimates.

The clinical study on which we modeled costs used a smaller sample size; therefore, we conducted a bootstrapped permutation-based test (to generate 500 samples) for verification purposes. We bootstrapped individual patient costs based on the values found in the clinical trial and costs found in the literature for our cost calculation and reported in Table 2 .
Table I Estimated Average Cost per Patient Treated with Tisseel for Anastomoses Closure versus No Fibrin Sealant for Closure in Spain

\begin{tabular}{|l|l|l|l|}
\hline Variable & Tisseel $^{\circledR}$ & $\begin{array}{l}\text { No } \\
\text { Treatment }\end{array}$ & $\begin{array}{l}\text { Cost } \\
\text { Difference }\end{array}$ \\
\hline Fibrin sealant & $€ 34 \mid$ & - & \\
Radiologic & $€ \mid 96$ & $€ 547$ & $-€ 35 \mid$ \\
Intervention & $€ 2$ & $€ 2$ & \\
RBC Transfusions & $€ 2$ & $€ \mid$ \\
Revision Surgery & $€ 438$ & $€ \mid 503$ & $-€ \mid 064$ \\
LOS & $€ 239 \mid$ & $€ 2524$ & $-€ \mid 33$ \\
Total & $€ 3368$ & $€ 4576$ & $-€ \mid 208$ \\
\hline
\end{tabular}

Abbreviation: LOS, length of stay.

Table 2 Independent Samples $t$-Test Results for Bootstrapped Data (Resampled 500 Times)

\begin{tabular}{|l|l|l|l|l|}
\hline Group & N & Mean & $\begin{array}{l}\text { Std. } \\
\text { Deviation }\end{array}$ & $\begin{array}{l}\text { Std. Error } \\
\text { Mean }\end{array}$ \\
\hline $\begin{array}{l}\text { Fibrin } \\
\text { Sealant } \\
\text { Control }\end{array}$ & 500 & $€ 872$ & $€ 444$ & $€ 20$ \\
\hline
\end{tabular}

We checked for equality of variances and found that the variances were not equal. A $t$-test was run for samples with unequal variances assumed, and we found that there was a statistically significant difference in means of $€ 1323$ (95\% confidence interval $95 \%$ CI: $€ 1277$ to $€ 1370$; $\mathrm{p}=0.000)$.

\section{Discussion}

The results are demonstrating the economic benefits of preventing AL by using fibrin sealant in colorectal surgery. However, it is important to consider the broader applicability of these findings to other GI surgeries. AL is a common complication in other types of anastomoses such as esophagojejunal surgery and surgeries of the pancreas and biliary tract. In a study that compared FS application after manual and stapled anastomoses, the postoperative leak rate in a study of 42 patients with gastrointestinal anastomosis was found to be $25 \%$ with minor leaks in 32 colorectal and esophagojejunal anastomoses prior to applying FS, and there were no leaks after FS application. ${ }^{34}$ FS has also been considered for preventing major complications such as leaks and re-intervention in laparoscopic Roux-en-Y gastric bypass (LRYGBP) surgeries. In a study of 320 patients (160 patients receiving FS treatment over gastrojejunal, jejunojejunal anastomoses, and over mesenteric openings, vs 160 
control patients), there was a statistically significant higher number of complications in the control group, and a suggested benefit in treating with FS for reducing reinterventions. ${ }^{37}$ The results of the literature search revealed the amount of evidence for this specific area of surgery was limited; however, FS has been compared with no treatment of FS for closing anastomoses in other surgical sites. We found 18 studies that compared Tisseel for the closing of anastomoses versus not using FS. One of the identified studies was for pancreaticoduodenectomy, ${ }^{28}$ and one was for esophagojejunal anastomosis, ${ }^{18}$ while the other 16 studies were for different procedures in the upper colorectum, including anal fistula repairs and laparoscopic gastric bypass surgeries. $^{1,2,7,10,13-16,19,26,27,32,36,37,40,41,44}$ Many of these studies suggest a relationship between FS and a reduction in leakages and other complications such as bleeding. However, these studies were not powered to find statistical significance in results. While some studies found results that suggest no benefit ${ }^{32}$ most gives a muted recommendation based on the fact that FS has no adverse effects, is not time-consuming to apply, and may be effective in preventing leaks and internal hernias. ${ }^{37}$

The type of surgery we analyzed is notable as there is a dearth of studies on anastomoses of the lower colon, perhaps due to the serious nature of leaks in the higher colon. However, the consequences of leaks in the rectum are still quite detrimental to patients and the treatments are very costly. Our results suggest that in colorectal surgeries requiring rectal anastomosis, the use of FS leads to costsavings by preventing the need for revision surgeries and radiologic interventions related to $\mathrm{AL}$. FS is a relatively low-cost preventative intervention, which can prevent costly revision surgery. It would be worth exploring through more robust clinical studies, whether its use results in the prevention of serious leaks requiring revision surgery. It would also be worthwhile to have studies that more transparently discuss the different alternatives to treating leaks. There is a great focus on revision surgery because it is the most serious and expensive reaction to a leak; however, it is more likely that most leaks are treated with a radiologic intervention. The literature search found few studies that report incidence rates of the radiologic intervention being used to treat leaks. This information would have been useful to our economic study.

The results described here are based on a single randomized controlled trial using a small sample conducted in Spain where FS was shown to reduce anastomotic leaks. To confirm this finding, additional clinical trials including a larger sample size would be needed. Therefore, it is important to understand how reflective the clinical data used in the economic model described here are applicable in other settings. In our search, we identified a case-control study reported by Kim et $a 1,{ }^{23}$ comparing fibrin sealant (1-2 mL) with no sealant in over 1000 cases of low anterior resection for rectal cancer. In this study, it was demonstrated that FS was an independent factor that predicted the prevention of AL. This study could have been used to model outcomes in the study described here; however, it was determined that using a European patient population would be more appropriate for the main parameter of interest - anastomotic leaks - for this economic assessment in Spain.

We recognize that extrapolating our results from different prospective studies carried out in various regions (South Korea, and Spain) is not ideal. A publication with a larger sample size which reports all outcomes of interest would have been more appropriate to use with Spanish cost data. However, our choice was made after conducting a thorough review of the literature and determining that no such studies were published. We also consulted with local doctors to inquire about other sources of data and found that, while there are some initiatives to collect this type of data, nothing has been published.

\section{Conclusion}

We conclude that using FS on the anastomosis is a favorable alternative to not treating the anastomosis during rectal surgery. Choosing to use FS leads to an estimated cost saving of $€ 1208$ per patient, after deducting the cost of the FS (approximately €341). The studies suggest that for a relatively low cost, lower rates of AL and other complications are found in groups treated with FS.

\section{Acknowledgment}

The authors would like to thank Therese De Serto-Cohen for her editorial assistance in preparing the manuscript.

\section{Disclosure}

S.P., M.P.C. and J.B.H received funding from Baxter Health Care to conduct this study. The study sponsor had no influence over the final published material. The authors maintained full editorial control over final published manuscript and its contents. M.G.R is an employee of Baxter Healthcare Corp., which is involved in the manufacture of a product examined in this analysis. The authors report no other conflicts of interest in this work. 


\section{References}

1. Adams T, Yang J, Kondylis LA, Kondylis PD. Long-term outlook after successful fibrin glue ablation of cryptoglandular transsphincteric fistula-in-ano. Dis Colon Rectum. 2008;51(10):1488-1490. doi:10.1007/s10350-008-9405-2

2. Altomare DF, Greco VJ, Tricomi N, et al. Seton or glue for trans-sphincteric anal fistulae: a prospective randomized crossover clinical trial. Colorectal Dis. 2011;13(1):82-86. doi:10.1111/j.14631318.2009.02056.x

3. Alves A, Panis Y, Pocard M, Regimbeau J-M, Valleur P. Management of anastomotic leakage after nondiverted large bowel resection. $J \mathrm{Am}$ Coll Surg. 1999;189(6):554-559. doi:10.1016/S1072-7515(99) 00207-0

4. Angelini P, Sciuto A, Cuccurullo D, Pirozzi F, Reggio S, Corcione F. Prevention of internal hernias and pelvic adhesions following laparoscopic left-sided colorectal resection: the role of fibrin sealant. Surg Endosc. 2017;31(7):3048-3055. doi:10.1007/s00464-016-5328-5

5. ASMBS. Prevention and detection of gastrointestinal leak. 2015. Available from https://asmbs.org/resources/prevention-and-detectionof-gastrointestinal-leak. Accessed May 2015, 03.

6. Atrah HI. Fibrin glue. BMJ. 1994;308(6934):933-934. doi:10.1136/ bmj.308.6934.933

7. Avalos-Gonzalez J, Portilla-deBuen E, Leal-Cortes CA, et al. Reduction of the closure time of postoperative enterocutaneous fistulas with fibrin sealant. World $J$ Gastroenterol. 2010;16 (22):2793-2800. doi:10.3748/wjg.v16.i22.2793

8. Averbach AM, Chang D, Koslowe P, Sugarbaker PH. Anastomotic leak after double-stapled low colorectal resection. Dis Colon Rectum. 1996;39(7):780-787. doi:10.1007/BF02054444

9. Briggs AH, Wonderling DE, Mooney CZ. Pulling cost-effectiveness analysis up by its bootstraps: a non-parametric approach to confidence interval estimation. Health Econ. 1997;6(4):327-340. doi:10.1002/(ISSN)1099-1050

10. Buchanan GN, Bartram CI, Phillips RK, et al. Efficacy of fibrin sealant in the management of complex anal fistula: a prospective trial. Dis Colon Rectum. 2003;46(9):1167-1174. doi:10.1097/01. Dcr.0000084408.85802.A2

11. Choi H-K, Law W-L, Ho JW. Leakage after resection and intraperitoneal anastomosis for colorectal malignancy: analysis of risk factors. Dis Colon Rectum. 2006;49(11):1719-1725. doi:10.1007/ s10350-006-0703-2

12. Daams F, Luyer M, Lange JF. Colorectal anastomotic leakage: aspects of prevention, detection and treatment. World $J$ Gastroenterol. 2013a;19(15):2293. doi:10.3748/wjg.v19.i15.2293

13. Daams F, Luyer M, Lange JF. Colorectal anastomotic leakage: aspects of prevention, detection and treatment. World $J$ Gastroenterol. 2013b;19(15):2293-2297. doi:10.3748/wjg.v19.i15.2293

14. de Oca J, Millan M, Jimenez A, Golda T, Biondo S. Long-term results of surgery plus fibrin sealant for anal fistula. Colorectal Dis. 2012;14(1):e12-e15. doi:10.1111/j.1463-1318.2011.02747.x

15. de Parades V, Far HS, Etienney I, Zeitoun JD, Atienza P, Bauer P. Seton drainage and fibrin glue injection for complex anal fistulas. Colorectal Dis. 2010;12(5):459-463. doi:10.1111/j.14631318.2009.01811.x

16. Del Rio P, Dell'Abate P, Soliani P, Ziegler S, Arcuri M, Sianesi M. Endoscopic treatment of esophageal and colo-rectal fistulas with fibrin glue. Acta Biomed. 2005;76(2):95-98.

17. Enker WE, Merchant N, Cohen AM, et al. Safety and efficacy of low anterior resection for rectal cancer: 681 consecutive cases from a specialty service. Ann Surg. 1999;230(4):544. doi:10.1097/ 00000658-199910000-00010

18. Fernandez Fernandez L, Tejero E, Tieso A. Randomized trial of fibrin glue to seal mechanical oesophagojejunal anastomosis. Br J Surg. 1996;83(1):40-41. doi:10.1002/(ISSN)1365-2168
19. Hammond J, Lim S, Wan Y, Gao X, Patkar A. The burden of gastrointestinal anastomotic leaks: an evaluation of clinical and economic outcomes. $J$ Gastrointest Surg. 2014;18(6):1176-1185. doi:10.1007/s11605-014-2506-4

20. Huh JW, Kim HR, Kim YJ. Anastomotic leakage after laparoscopic resection of rectal cancer: the impact of fibrin glue. Am J Surg. 2010;199(4):435-441. doi:10.1016/j.amjsurg.2009.01.018

21. Ielpo B, Duran H, Diaz E, et al. Robotic versus laparoscopic surgery for rectal cancer: a comparative study of clinical outcomes and costs. Int J Colorectal Dis. 2017;32(10):1423-1429. doi:10.1007/s00384017-2876-7

22. Jörgren F, Johansson R, Damber L, Lindmark G. Anastomotic leakage after surgery for rectal cancer: a risk factor for local recurrence, distant metastasis and reduced cancer-specific survival? Colorectal Dis. 2011;13(3):272-283. doi:10.1111/codi.2011.13.issue-3

23. Kim HJ, Huh JW, Kim HR, Kim YJ. Oncologic impact of anastomotic leakage in rectal cancer surgery according to the use of fibrin glue: case-control study using propensity score matching method. Am J Surg. 2014;207(6):840-846. doi:10.1016/j.amjsurg.2013.07.047

24. Konishi T, Watanabe T, Kishimoto J, Nagawa H. Risk factors for anastomotic leakage after surgery for colorectal cancer: results of prospective surveillance. J Am Coll Surg. 2006;202(3):439-444. doi:10.1016/j.jamcollsurg.2005.10.019

25. Liberati A, Altman DG, Tetzlaff J, et al. The PRISMA statement for reporting systematic reviews and meta-analyses of studies that evaluate health care interventions: explanation and elaboration. PLoS Med. 2009;6(7):e1000100. doi:10.1371/journal.pmed.1000100

26. Lippert E, Klebl FH, Schweller F, et al. Fibrin glue in the endoscopic treatment of fistulae and anastomotic leakages of the gastrointestinal tract. Int J Colorectal Dis. 2011;26(3):303-311. doi:10.1007/s00384010-1104-5

27. Liu CD, Glantz GJ, Livingston EH. Fibrin glue as a sealant for high-risk anastomosis in surgery for morbid obesity. Obes Surg. 2003;13(1):45-48. doi:10.1381/096089203321136575

28. Martin I, Au K. Does fibrin glue sealant decrease the rate of anastomotic leak after a pancreaticoduodenectomy? Results of a prospective randomized trial. HPB (Oxford). 2013;15(8):561-566. doi:10.1111/ hpb. 12018

29. Navarra OGO. RESOLUTION 626/2014, of June 5, of the managing director of the navarra health Service-Osasunbidea, by which rates are updated for the services provided by the Navarre Health Service-Osasunbidea., - Official Gazette of Navarra, of 0907-2014. 2014. Available from https://www.iberley.es/legislacion/ resolucion-626-2014-5-junio-director-gerente-servicio-navarro-saludosasunbidea-actualizan-tarifas-servicios-prestados-servicio-navarrosalud-osasunbidea-14487613. Accessed July 2014, 09.

30. NHLBI. Study quality assessment tools $\mid$ National Heart, Lung, and Blood Institute (NHLBI). 2018. Available from https://www.nhlbi.nih. gov/health-topics/study-quality-assessment-tools. Accessed December 2018, 21.

31. Oliver JL, Garijo SA, Estéves MB, Ayuso MC, Fuentes FT, Gómez AC. The systematic use of fibrin-based biological adhesive to prevent leakage due to healing defects in rectal anastomosis significantly reduces costs. J Surg. 2015;3(2):12-17. doi:10.11648/j.js.20150302.12

32. Pandanaboyana S, Bell R, Shah N, et al. A cost-effective analysis of fibrin sealants versus no sealant following open right hemihepatectomy for colorectal liver metastases. ANZ J Surg. 2017;87(6):E11e14. doi:10.1111/ans. 12948

33. Ribed-Sánchez B, González-Gaya C, Varea-Díaz S, CorbachoFabregat C, Pérez-Oteyza J, Belda-Iniesta C. Economic analysis of the reduction of blood transfusions during surgical procedures while continuous hemoglobin monitoring is used. Sensors (Basel). 2018;18 (5):1367. doi:10.3390/s 18051367

34. Romeo G, Basile F, Giannone G, Iuppa A, Sandonato L, Chiarenza OE. Use of Fibrin Sealant (Tissucol/Tisseel) in Manual and Stapled Anastomoses. Berlin, Heidelberg: Springer; 1986. 
35. Senol M, Altintas MM, Cevik A, et al. The effect of fibrin glue on the intensity of colonic anastomosis in the presence and absence of peritonitis: an experimental randomized controlled trial on rats. ISRN Surg. 2013;521413. doi:10.1155/2013/521413

36. Sentovich SM. Fibrin glue for anal fistulas: long-term results. Dis Colon Rectum. 2003;46(4):498-502. doi:10.1097/01.Dcr.0000059658.99412.3c

37. Silecchia G, Boru CE, Mouiel J, et al. The use of fibrin sealant to prevent major complications following laparoscopic gastric bypass: results of a multicenter, randomized trial. Surg Endosc. 2008;22 (11):2492-2497. doi:10.1007/s00464-008-9885-0

38. Thomas MS, Margolin DA. Management of colorectal anastomotic leak. Clin Colon Rectal Surg. 2016;29(2):138-144. doi:10.1055/ s-0036-1580630

39. TISSEEL Ready to use Solutions for Sealant - Summary of Product Characteristics (SmPC) - (eMC). 2019. Available from https://www. medicines.org.uk/emc/product/1801/smpc. Accessed January 2019, 04.

40. Torres-Melero J, Motos-Mico JJ, Lorenzo-Linan M, MoralesGonzalez A, Rosado-Cobian R. [Use of absorbable fibrin sealant patch to strengthen the gastrointestinal anastomosis performed on patients with peritoneal carcinomatosis treated with intention to cure by debulking surgery and intraoperative hyperthermic intraperitoneal chemotherapy]. Cir Cir. 2016;84(2):102-108. doi:10.1016/j. circir.2015.09.005
41. Tsuji Y, Ohata K, Gunji T, et al. Endoscopic tissue shielding method with polyglycolic acid sheets and fibrin glue to cover wounds after colorectal endoscopic submucosal dissection (with video). Gastrointest Endosc. 2014;79(1):151-155. doi:10.1016/j.gie.2013.08.041

42. Turrentine FE, Denlinger CE, Simpson VB, et al. Morbidity, mortality, cost, and survival estimates of gastrointestinal anastomotic leaks. $J \mathrm{Am}$ Coll Surg. 2015;220(2):195-206. doi:10.1016/j.jamcollsurg.2014.11.002

43. Vignali A, Fazio VW, Lavery IC, et al. Factors associated with the occurrence of leaks in stapled rectal anastomoses: a review of 1014 patients. J Am Coll Surg. 1997;185(2):105-113. doi:10.1016/S10727515(97)00018-5

44. Yeung JM, Simpson JA, Tang SW, Armitage NC, MaxwellArmstrong C. Fibrin glue for the treatment of fistulae in ano-a method worth sticking to? Colorectal Dis. 2010;12(4):363-366. doi:10.1111/j.1463-1318.2009.01801.x
Risk Management and Healthcare Policy

\section{Publish your work in this journal}

Risk Management and Healthcare Policy is an international, peerreviewed, open access journal focusing on all aspects of public health, policy, and preventative measures to promote good health and improve morbidity and mortality in the population. The journal welcomes submitted papers covering original research, basic science, clinical \& epidemiological studies, reviews and evaluations,

\section{Dovepress}

guidelines, expert opinion and commentary, case reports and extended reports. The manuscript management system is completely online and includes a very quick and fair peer-review system, which is all easy to use. Visit http://www.dovepress.com/testimonials.php to read real quotes from published authors. 